\title{
Encouraging ESL learners to speak English in large classes towards the combining arrangement activities
}

\author{
Chomkate Ngamkaiwan * \\ International Demonstration School, Mahidol University , Nakhon Pathom, Thailand
}

\author{
Keywords \\ ESL learners \\ Combining arrangement \\ Large classes \\ Speaking opportunities
}

Received: 9 April 2018

Accepted: 19 May 2018

Published: 8 June 2018

\begin{abstract}
This action research aims to explore how to promote English speaking opportunities among the English as Second Language (ESL) learners in large classes towards the application of the combining arrangement activities. The research design followed the mixed methods in which surveys and documentary analysis were used for the data collection process. The samples in this study were 48 Grade 11 students in an international demonstration school. According to the research results, there was a $21 \%$ increase in the number of students who often participated in English speaking activities while there was a $26 \%$ decrease in the number of students who only sometimes participated in such activities. Compared to the pre-intervention period, although $52 \%$ felt neutral towards the following statement, $46 \%$ of the students supported that the intervention activities effectively increased their English speaking opportunities in class. Regarding the design of the intervention activities, their common features include split information, individual task, mutual dependency, E-shape seating arrangement, direct communication, self-reflection, individual grading, problem-solving or critical thinking experiences, and entertaining or interesting content. In this research, the invention activities were mostly simulation games, role-plays and role-played speeches, and case-based group discussions, which encouraged the students to communicate with the whole class in English, learn new vocabularies and expressions, promote competitiveness and teamwork, and reduce the learners' stress with fun and low-pressure environment.
\end{abstract}

\section{INTRODUCTION}

A 'large class' cannot be quantitatively defined since its definition can be varied from context to context (Hayes, 1997). Teachers working in international schools may expect classes of ten to 15; for them 20 or more is often seen as too large. On the contrary, a class of 25 would be warmly welcomed by common public high schools. According to Negash and Shamim (2007), the perceptions of large classes are shaped by the factors that go beyond numbers. Teachers may recognize a large class when they are concerned about providing unequal an opportunity to all learners which becomes an issue of classroom management, while the learners may also identify the lack of opportunities to participate in classroom activities as a 'large class' problem.

Caused by a number of limitations, ESL learners in large classes tend to be challenged by the lack of opportunities and motivation to speak English. According to the survey conducted by Al-Jarf (2006), most of the research participants agreed that they did not have enough time to pay attention to each student or present effective activities to give all of them a chance to speak or participate, especially the weak or shy ones (Abdul Amir, 2015; Bahanshal, 2013; Hilao, 2016; Junnak \& Veerachaisantikul, 2016). Moreover, Yu (2004) pointed out that limited time to practice the target language due to the large number of students handicapped students from enhancing their level of oral English. Harmer (2008) also affirmed that large-class teachers tended to find it burdensome to organize effective and creative activities to allow all students to speak. Correspondingly, researchers such as DiNitto (2000) and Long and Porter (1985) claim that one major cause of low proficiency of many ESL learners is simply because of the insufficient time they can practice the language (Lin, 2015). According to Ky (2002), a teacher might argue that trying to call on everybody in the

\footnotetext{
*corresponding author: Chomkate Ngamkaiwan
}

†email: kathy.muids@gmail.com 
class to answer the questions or do the presentations would take too much time. The lesson would never be completed, and disengaged students would get bored and begin to do something else. Another major problem affecting the students' engagement in speaking practice in class is the differences in background knowledge, including English proficiency. Large classes are usually highly heterogeneous. Ky (2002) stated that while some students can fluently express their opinions about various topics, others might find it difficult or uncomfortable to speak out; this problem may also occur when students are not interested in these problems or do have enough prior knowledge about some common cultural, social, or political issues. In this research, the author defined a large class as "a classroom of any size that confronts with limitations or unequal opportunities in terms of learning the content or practicing certain skills".

However, reducing the class size is not always a possible option in some teaching context, for example, the dependence on the increasing number of enrolled students, time limit, and the lack of personnel or facilities. Bahanshal (2013) asserted that even though teachers believe it is tremendously crucial to downsize the number of students in classes, they admit that it is necessary to explore alternative teaching strategies for encouraging students to speak English in big groups. Therefore, the goal of this study is to combat the lack of speaking opportunities in large classes without losing students' active participation by applying the idea of combining arrangement activities.

\section{Research Questions}

As the lack of speaking opportunities in large classes is a major problem in many educational institutions, this study attempts to answer the following questions:

1. Can combining arrangement activities effectively promote English speaking opportunities in large classes?

2. What are the essential elements of the design of combining arrangement activities used for increasing English speaking opportunities among the ESL learners in large classes, especially for the non-linguistics courses like world history?

3. What kind of combining arrangement activities can effectively promote English speaking opportunities in large classes and increase students' learning motivation simultaneously?

\section{LITERATURE REVIEW \\ Definition of ESL Learners}

According to the Department of Education and Early Childhood Development of Newfoundland and Labrador (2009), an ESL learner is "a student whose primary language or languages of the home is other than English and would require additional English language support to develop reading, writing, listening and speaking skills". Generally, this kind of students comes from various linguistic and cultural backgrounds. In this research, ESL students in international schools who mainly speak English for the purpose of study are emphasized.

\section{Collaborative Learning Approach}

From the functionalist perspective, a society is composed of different institutions working together by performing their duties in order to achieve the common interests of the citizens. In the same manner, when a group task is assigned, students are expected to handle their roles and responsibilities to finish the task together. This is conformed to the study written by B. L. Smith and MacGregor (1992) which suggested that 'collaborative learning' means an educational setting where students are working in groups of two or more, mutually searching for understanding, solutions, or even creating a product. In other words, under this condition, students will "learn or attempt to learn something together" (Lin, 2015). Therefore, in this context, teachers who use collective learning may consider themselves as 'expert designers of intellectual experiences' for students rather than expert transmitters of knowledge (Boonyarattanasoontorn, 2017; Charoensuk \& Jaipetch, 2017; B. L. Smith \& MacGregor, 1992; Taher, Shrestha, Rahman, \& Khalid, 2016).

Nonetheless, it is important to understand the difference between 'collaborative learning' and 'cooperative learning'. K. A. Smith, Sheppard, Johnson, and Johnson (2005) defined cooperative learning as the instruction that requires both interdependence and individual accountability to accomplish a common goal since all members must help one another to complete the task and each member is also responsible for the complete final outcome. In this regard, group work or cooperative learning would be described as "the division of labor among participants, as an activity where each person is responsible for a portion of the problemsolving"; in other words, the members may not necessarily need to learn one another's duties and may not fully understand the whole process of learning. In contrast, collaborative learning requires "mutual engagement of members in a harmonized effort to solve the problem together". Woolfolk (2004), hence, concluded this notion as follows: "group work can be still effective in teaching, but real collaborative learning can give much more than simply putting students in groups". In addition, Miyake (1986) even elab- 
orated the role of observers who could contribute to the learning sphere along with the task-doers by which they could take non-primary roles in the activity, for example, criticizing and giving topic-divergent motions to the class. In this research, switching roles between task-doers and observers (or 'taking turns') is also a key to collaborative learning.

\section{Teaching Strategies for Large Classes}

According to "Encourage Learners in the Large Class to Speak English in Group Work”, written by Meng (2009), there are several classroom management strategies based on collaborative learning theory suggested for promoting students' ability in speaking in the large class which are 1) superior-inferior arrangement, 2) co-operating arrangement, 3) individual arrangement, and 4) combining arrangement.

\section{Superior-inferior arrangement}

In large classes, the superior-inferior relationship is conducted in the way that one or two students, in the superior position, have all the information that other students need or know what the correct answers should be (Meng, 2009). This means there is the inequality in their background knowledge before the activity begins. For example, in one of the researcher's lessons, several learners were selected to be the activity instructors. Each of them was assigned to study how to teach a stress relief technique outside classroom or possibly at home, and then demonstrate the technique to their classmates. They were also responsible for monitoring how well their classmates learned and performed the techniques at their stations. Under such circumstances, even though the learners can change their roles, not all the students can perform the roles of instructors due to the limited number of duties, unequal proficiency of the learners, and accountability of the instructors. In regards to speaking opportunities, it is clear that the superior learners have more opportunities to speak or practice the new technical vocabularies and master the content while the rest of the class may have no or little chance to do so.

\section{Co-operating arrangement}

In contrast to the superior-inferior arrangement, students under the co-operating arrangement have the equal access to the same information and to each other's points of view. This approach allows the learners to share their understandings and solutions of the assignments or the materials used in the activities, and help each other to complete the task. For instance, a teacher may assign a problem-solving activity to groups of students. Students are expected to use their personal, moral or social knowledge as useful materials for group discussion. According to Hill (1982), this kind of arrangement is favorable if there is some degree of equality between learners, especially an essential equality of skill because the group performance may not be compatible to the best individual's performance if there is an extraordinary individual in the group (Meng, 2009). Therefore, for co-operating arrangement, it is more beneficial to put the best learners in one group rather than to spread them across groups. However, this approach may be not suitable for large-class settings, where the gap between students' proficiency is wide in particular, since it could result into non-participation of some students and affect the speaking opportunities of some students. Hence, it may be not preferred by some educational institutions that expect cooperation between learners.

\section{Individual arrangement}

Individual arrangement activities are often used in conventional teaching and still plays a big role even in a studentcentered environment. In this kind of activity, each student has the access to the same information but performs their task individually with that piece of information. The researcher had used the individual arrangement in one of her lessons by assigning each student to perform as a historical figure who will retell his/her story to the world. It is a good speaking activity because it not only allows an extensive range of language functions and varieties to occur, students can also discover a variety of knowledge sets which add interest to the activity. However, this approach has a number of disadvantages such as the risk of embarrassment, the absence of cooperation or assistance, and lack of engagement or interactions between students. Students usually focus on their individual tasks and may not provide the class with the equally-qualified products.

\section{Combining arrangement}

In this study, the combining arrangement approach (which usually includes jigsaw groups, two-way tasks, or information gap activities) is highlighted as the most suitable classroom management strategy for promoting speaking opportunities in large classes compared to the other three approaches stated in the previous section.

According to Meng (2009), students under the combining arrangement condition are all on an equal footing since each of them has unique essential information that the others need in order to accomplish a task. This means students are obliged to communicate with each other so that all the 
information can be combined and the quality of the complete product will be verified before its submission or exhibition. This kind of classroom management strategies usually involves split information activities in which students are provided with a balance of particular fundamental information between them; different kinds of materials may be used such as the combination of a written text, a picture or pictures, text and pictures, and so on (ibid). To illustrate, a strip story is a common activity that involves split information technique. The story will have to be separated into various strips of sentences or passages or pieces of texts, depending on the level of the students. Each learner has to memorize or analyze his/her part before telling or explaining it to the others in the group. Afterwards, all the learners must organize themselves to put the story together or solve the assigned problem.
Thus, students not only enhance their fluency while participating in the activities, but also master the new content or language items that they individually got. Therefore, it can be concluded that combining arrangement can ensure active participation of all students, encourage more use of communication strategies and feedback, boost up students' learning motivation and attitude, and suit more students' learning style preferences. By using combining arrangement activities with small groups within a large class or the whole class work together under the same circumstances, it is possible to engage more low proficiency students into speaking activities. This research, hence, aims to offer alternative classroom activities based on the combining arrangement approach in order to increase the speaking opportunities in large ESL classes.

TABLE 1. Differences between large classroom arrangement approaches (Lin, 2015; Meng, 2009)

\begin{tabular}{|c|c|c|c|c|}
\hline & Combining & Co-operative & Superior-Inferior & Individual \\
\hline $\begin{array}{l}\text { Distribution of In- } \\
\text { formation }\end{array}$ & $\begin{array}{l}\text { Each learner has } \\
\text { particular, funda- } \\
\text { mental information }\end{array}$ & $\begin{array}{l}\text { All learners have } \\
\text { equal access to the } \\
\text { same information } \\
\text { and to each other's } \\
\text { view of it }\end{array}$ & $\begin{array}{l}\text { One or more learn- } \\
\text { ers have the infor- } \\
\text { mation that the oth- } \\
\text { ers do not have }\end{array}$ & $\begin{array}{l}\text { All learners have } \\
\text { the same infor- } \\
\text { mation but use } \\
\text { it differently or } \\
\text { individually use it. }\end{array}$ \\
\hline Social Relationship & $\begin{array}{l}\text { Equality; mutual } \\
\text { dependency }\end{array}$ & Equality & $\begin{array}{l}\text { Inequality; the su- } \\
\text { perior has more in- } \\
\text { formation }\end{array}$ & $\begin{array}{l}\text { Equality; focus on } \\
\text { individual perfor- } \\
\text { mance }\end{array}$ \\
\hline $\begin{array}{l}\text { Most Suitable } \\
\text { Learning Goals }\end{array}$ & $\begin{array}{l}\text { Mastery of content } \\
\text { and/or fluency }\end{array}$ & $\begin{array}{l}\text { New language items } \\
\text { Fluency }\end{array}$ & $\begin{array}{lr}\text { New language } \\
\text { items; mastering } \\
\text { content }\end{array}$ & $\begin{array}{l}\text { Fluency; new lan- } \\
\text { guage items }\end{array}$ \\
\hline
\end{tabular}

\section{Suitable Conditions for Combining Arrangement}

Generally speaking, it is necessary to create a relaxed and accessible classroom environment to encourage the students to speak out, especially for ESL learners. In order to promote such circumstances, teachers usually consider different kinds of seating arrangements to design a comfortable place for teaching and learning process. Marzano, Marzano, and Pickering (2003) noted that a good seating chart should allow the teachers see all students and vice versa. Students must be able to comfortably see all presentations and demonstrations by which the pathways do not cause traffic issues. The arrangement must allow students to easily get in pairs or small groups (Mala, 2004).

According to "the Effect of U-Shape (Horseshoe) Seating Arrangement on Speaking Ability of the Tenth Grade Students at SMK TI Airlangga Samarinda" written by (Mala, 2004), the U-shape seating arrangement (Figure 1) is suit- able for informal teaching, especially student-centered environment. Mala reaffirmed that this seating arrangement could be the best option for whole-class or group discussions or better student-teacher and student-student interactions because under this kind of conditions the teacher can give a demonstration in front of class in which all students can see and hear the explanation clearly. Additionally, with this kind of arrangements, teachers can also monitor each student's engagement (either by listening to or speaking with their classmates) more conveniently. In the same manner, another study written by Minchen (2007) supported that U-shape seating chart can constitute the greater interaction between the teacher and the students and between the students themselves. It can positively increase participation in class since it provides space for easier classroom discussion, presentations, debates, and role playing activities. In brief, this layout is appropriate for collabora- 
tive learning as it promotes togetherness, avoids exclusion, and encourages interactive activities.

Nonetheless, enough space is crucial for this kind of seating arrangement; it is more appropriate for a classroom with 15-20 students or lesser. In order to cope with the U-shape seating arrangement limitations, E-shape seating chart (Figure 1) was developed. According to Mount Allison University, this kind of seating arrangement is a modi- fication of the U-shape to make room for more students. It provides sufficient space in the center for students to walk around. Therefore, this configuration is suitable for both large classes and interactive English speaking activities. In this research, the E-shape seating chart was used as a condition set for implementing the designed combining arrangement activities.
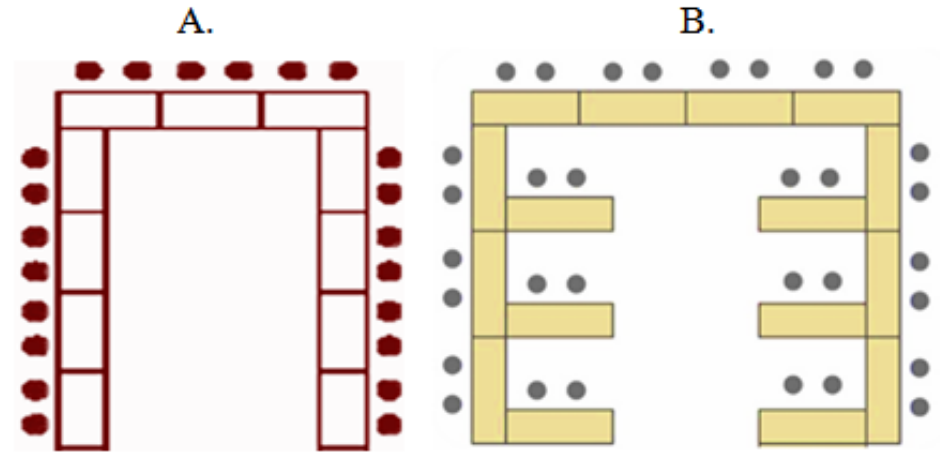

FIGURE 1. U-shape arrangement (A) and E-shape arrangement (B)

\section{Previous Studies}

Azmin (2016) studied the effect of the jigsaw-based cooperative learning (or combining arrangement) method on student performance in psychology class in Brunei. She noted that, according to Johnson and Johnson (1999), there are five significant elements that must be borne in mind in order to create effective and favorable collaborative learning which are 1) positive interdependence, 2) individual accountability, 3) face-to-face interaction, 4) interpersonal and small group skills, and 5) group processing. The positive interdependence refers to the common goals that the learners pursue together while individual accountability means the individual responsibility and commitment. These two elements are often mentioned in the majority of the collaborative learning studies, including Slavin (1988). However, Johnson and Johnson suggested that it is necessary to have direct communication between the learners as well as teamwork capabilities such as problem solving, compromisation, feedback giving, and so on. More importantly, students must be able to reflect their learning process as a group which includes their success, failure, and required improvements.

In this study of Azmin (2016), she recommended a variety of collaborative learning approaches suitable for large classes that are usually heterogeneous in terms of skills and language competency. First, in order to maintain the fairness, a principle of Student Teams-Achievement Division (STAD) method should be applied by which students are encour- aged to cooperate to enhance the overall performance of the group, but they are graded individually based on their contribution to the group task. Second, the Teams-GamesTournaments (TGT) technique offers an equal opportunity to gain positive reinforcement from fellow learners as it can spark the competitive spirit and provide an entertaining atmosphere from the popularity of the game. Last, the Jigsaw Method is also very popular among the teachers; students are divided into groups, and assignments are broken down into pieces in which each group assembles to complete the (jigsaw) task. Generally, with the Jigsaw Method, students are required to study given readings or materials, and then leave their 'home groups' to form 'expert groups' in order to share and discuss their findings from their home bases with other experts. Azmin also asserted that this kind of collaborative arrangement strategies could effectively increase the students' self-esteem, competency, and engagement. Nevertheless, some advanced students might find the jigsaw method uninteresting because the context would be too simple for them. So, in order to maintain their motivation, it is necessary to balance the level of difficulty combining with the competitive opportunities and individual grading distribution as offered by STAD and TGT methods. $\mathrm{Su}$ and Liang (2017) conducted an action research on "the Multiple Intelligence (MI), Cooperative Learning, and Game-based Teaching into Summer Intensive English Classes for Mixed-level and Mixed-age Students". The research results demonstrated the effective use of games in 
the classroom since it can increase the students' interest and learning motivation for practicing English speaking skills. According to this study, students tend to cooperate with their teammates by not only completing their tasks, but also using cognitive mechanisms towards interactive activities. There are some key components of collaborative learning such as specific instructions to group the learners together, a physical setting like the suitable seating arrangement, and other institutional constraints (for example, different grade distribution criteria which include both individual and group marks). In other words, this collaborative conditions can be referred to a kind of social contract that guarantees the contributions from all students. In this reviewed action research, the authors found out that students liked to ask for playing games regularly or frequently as they were willingly encouraged to perform particular types of interaction and explore new learning towards games. Well-designed games should provide problem-solving experiences, reduce the learning pressure, and give opportunities to the students to use particular vocabulary or sentence patterns more effectively.

\section{Hypotheses Development}

The previous subsections presented existing empirical evidence and theories in regards to the effective usage of the combining arrangement approach as well as its key features. It thus formulates the basis for the hypotheses of this research as follows.

H1: Classroom activities comprise of combining arrangement strategy characteristics can promote English speaking opportunities among ESL students in large classes.

H2: E-shape seating arrangement can effectively support the application of the combining arrangement activities.

\section{METHODOLOGY}

This research was conducted at an international demonstration school in Thailand. It serves 562 10th-12th graders in which $98.6 \%$ of them are Thai while the teachers are predominantly Thai and American (each 34\%) with the remainder representative of nine other nationalities. Although it is an international demonstration school, its curriculum is a combination of Thai and American standards which include core courses such as English, Math, World History, General Science Courses, Thai Studies, and so on and a range of elective courses ranged from advanced sciences to business studies.

The target population of this research is the ESL learners whose home language is Thai. Therefore, reading, writing and speaking proficiency in English is a major issue for the majority, even though the school's admission requirements include a minimum TOEFL score of 450 . Most of the time, the students actively experience with a variety of listening, reading, and writing assignments; however, they are persistent in using their native language when talking or discussing with their classmates.

In this study, the samples were 48 students from the researcher's class which is World History II for Grade 11. One of the students is half Thai-English while the others' nationality is Thai.

\section{Research Process}

In this action research, both quantitative and qualitative methods such as surveys and documentary analysis were used for collecting the data. The researcher used the descriptive statistical analysis to analyze the quantitative data, and the content analysis to interpret the records from students' reflection notes.

Step 1 First of all, according to the researcher's participant observation and reviewed literatures, the lack of speaking opportunities in large classes, especially for the ESL learners, is a major problem in today's education. Documentary analysis focusing on common classroom management styles for large classes was exercised to develop the hypotheses.

Step 2 The researcher used a pre-intervention survey to collect data and information about the target group's opinions on their current situation regarding the problem as well as their suggestions and preferences in order to design classroom activities that can suitably increase their speaking opportunities in large classes.

Step 3 Descriptive statistics were used for describing the survey results. The findings were interpreted in correlation with the reviewed literatures.

Step 4 After reviewing the literatures and analyzing the survey results, the researcher modified her lesson plans and classroom activities in correspondence with the findings. Afterwards, the research experimented the classroom activities with the samples (intervention).

Step 5 Another survey (post-intervention) was conducted to find out the students' opinions on their speaking opportunities in large classes after the intervention. The researcher compared the survey results with the students' reflection results, discussed them, and made a conclusion. Lastly, future recommendations were implemented for the anticipated lessons or further studies. 


\section{Data Collection Tools}

There were two major data collection tools used in this study: surveys and students' reflection notes. For the pre-intervention survey, the questions mostly focused on the students' English speaking experiences in class and their preferences for speaking activities. For the postintervention survey, the researcher revised some questions in the first survey in order to find out the changes in their thoughts and behaviors after the intervention, for example, what their favorite activities after the intervention are. Moreover, the researcher used the students' reflection notes for supporting the discussion of the statistical analysis results from the surveys. The researcher's observation was also used for elaborating the quantitative and qualitative data from the surveys and students' reflection notes.

\section{Duration}

The study had been conducted for 6 months. The first survey was carried out in December 2017. Then, the intervention started in January 2018 and ended in March 2018. The second survey was carried out in April 2018. The report was finalized in May 2018, in other words, at the end of the academic year 2017/18.

\section{INTERVENTION}

In this study, the action research intervention involved gathering data on the English speaking opportunities in two large classrooms through out four months. The researcher had designed different classroom activities for each lesson using the combining arrangement strategy in order to increase the English speaking opportunities among the ESL students in large classes. The researcher also played the role of the teacher who independently conducted the alternative classroom activities - the proposed innovation of this project.

\section{Activity Design}

According to the reviewed literatures, the essential elements of the combining arrangement strategy are 1) split information, 2) individual task, and 3) mutual dependency. The researcher has focusedly designed a number of classroom activities that involved these three qualities. In order to promote speaking opportunities in class, the researcher also added speaking tasks required for each student to achieve their final product in the end altogether. On top of that, the researcher had organized the classroom environments in the way that supported combining arrangement strategy by using E-shape seating chart in order to create spaces and easy pathways for students to perform group activities and whole-class discussions. In addition, accord- ing to the previous studies reviewed in Section 2.7, apart from mutual dependency and individual task, students are obliged to directly communicate with one another and commit to self-reflection on the learning process. They will be graded individually to maintain fairness, and learn towards fun activities like games which provide breakthrough problem-solving or critical thinking experiences with low learning pressure. However, it is still necessary to examine the students' preferences on oral activities in class beforehand.

From the pre-intervention survey, out of 37 students, it has been found that 23 students (62\%) were comfortable or very comfortable enough to answer a question in front of the class. $80 \%$ were comfortable or very comfortable to speak English with their partners in pair while $84 \%$ were comfortable or very comfortable to have a small group discussion in English. This indicated that more than half of the students were likely to converse or discuss in English when necessary. Furthermore, $78 \%$ of the students preferred to do speaking activities in pair or with a small group of three or four classmates, and $14 \%$ of them preferred to do the activities with the whole class (about $8 \%$ or three students, in particular, did not answer this question). From the researcher's observation, students with high proficiency tended to benefit more from the deep and energetic discussions in small groups while students with lower proficiency were prone to speak out only when the whole class actively engaged. In the same manner, 4 students confirmed that they would be more motivated to participate in English Speaking activities in class if everyone tries their best or a lot of people engage in the activity. Additionally, a student stated in the survey that students are likely to engage more in a classroom activity if the teacher is involved as a player, a member, or a stakeholder in the activity.

In the same survey, regarding their preferred types of classroom activities, students were asked to identify their favourite English speaking activities that had been offered during the first semester of this academic year. They were also asked to give examples of activities that can increase their motivation to participate in English speaking activities in class, 15 students (31\%) stated that their favorite speaking activities that had been offered in their World History class were role plays and simulations, and 9 students (19\%) preferred group discussions. Interestingly, 2 students mentioned whole-class activities as their favorite. Again, this has conformed to the fact that some students said they would be more motivated if a lot of people or everyone in the class actively participate in the activity. Moreover, 10 students (21\%) proposed that games and/or fun activities 
like simulations or debates can increase their motivation. Furthermore, it is important to note that 11 students (23\%) considered prizes, for example, candies or bonus points as some good incentives. Regarding in terms of the time limitation in class, $65 \%$ of the students stated that they had had enough time to prepare when the teacher organized an activity. There were six students who asserted that they did not have enough time, and two students who said they had too much time. This means if the teacher continued giving the same amount of time or more time to students to work on their tasks, the majority would be able to complete the tasks in time.

To summarize, according to the survey results, the researcher should increase more game or simulation activities as well as group discussions or debate in both small and large groups in order to engage all students (low-proficient and high-proficient) in oral activities. The students will be given unique pieces of information that must be used for completing the final product together in group. The teacher should play an active role in the activity in order to make some students feel more comfortable to speak out. The researcher may have to give more time for each activity since the low-proficient students would need more time to digest their given pieces of information individually. Extra points should be given in order to encourage the advanced communication skills or increase students' engagement in overall.

\section{Conducting the Activities}

The researcher had introduced various activities in every lesson based on the combining arrangement strategy in the second semester of this academic year, except the selfdirected project period. These activities could be categorized into three major types: 1) simulation games, and 2) role-play debate and 3) case-based group discussions. They were designed to have some common role-playing features (i.e. plots, assigned characters or duties) in order to increase students' learning motivation. In this research, some assignments were selected as the illustrations

\section{Example 1 imperialism simulation board game}

At the beginning of Semester 2, students had to recall the meanings of imperialism, nationalism, and the Industrial Revolution and understand how the mentioned ideas can lead to conflict towards the use of a simulation board game. In this simulation, students were organized in groups of 4 to play a board game where they were acting as the generals of the 'great powers' in a continent trying to gain more resources and colonies. In this activity, the essential elements of the combining arrangement strategy were applied with regard to speaking opportunities.

\section{Split information}

While playing this board game, students were provided with three kinds of standard cards indicating three kinds of moves in this game: mobilize the army, upgrade the weapons/vehicles, and attack, and drew some special cards from the card deck that can facilitate/disrupt your expansion. The special cards consist of the information about the concepts of 'alliance', 'new inventions', 'anti-war movement', 'colonial resistance', and 'dual monarchy resistance' which were the key vocabularies in this class. Every time that a special card was drawn by a representative of each group, the representative must explain the card and how it is related to his/her group's situation.

\section{Individual task}

Students must take turns to announce their moves throughout the game. For example, in each team, there are four members. A member may announce their army's mobilization in a round to the whole class. Then, another member may announce their attack on another team in the next round. Moreover, each student needs to take turns to draw a special card from the card deck and explain how the card will affect his/her team's situation to the class.

\section{Mutual dependency}

Students need to clearly announce their moves and explain the effects of the special effects to the class because these pieces of information can affect their decision-making while playing this game. Extra marks shall be given to the winning team. Furthermore, as students have to analyze the game for their reflection, including how the events described in the special cards affected their victory or defeat, the pieces of information split among the students were crucial.

\section{Example 2 causes of the world war I role-play debate}

For this debate activity, students had spent six periods to prepare and perform the debate by analyzing the events leading up to World War I and identifying the roles, relationships, goals, and ambitions of the countries involved. It was a fun activity as there was a storyline behind it and students had to play the role of each country's representatives who could point fingers at other countries and blame them for causing the war. In terms of the debate structure, students were separated into 6 teams based on the main countries involved at the beginning of WWI. Each student had a role either as a debater or Q\&A interrogator from each 
team so that every student had a chance to engage in public speaking effectively. The combining arrangement principles were also applied to this extensive oral activity.

\section{Split information}

Students have to research about their own assigned parts before sharing the information in group in order to prepare for the debate. For instance, 1-2 members have to find the information needed for the opening statement, or the reasons why their country was innocent in terms of the war's escalation in particular. Whilst, other member research about other faults that led to the war in order to rebut the other teams. This information will be shared not only within their group, but also their classmates during the debate. It is necessary because each student has to individually submit his/her debate summary, which involves the reasons why each team thinks they weren't the one to start the war and what s/he thinks about each team's justifications.

\section{Individual task}

Students are separated into groups of four. There are three debaters (for opening statement, rebuttal, and closing statement, respectively) and one Q\&A (questions and answers) interrogator in each group. One of the common limitations of the debate activities in schools is the fact that the number of students may be not divisible by three. So, the researcher applied the role of 'observers' into this activity by adding a Q\&A interrogator into each team. The role of Q\&A interrogators is crucial because they are in charge of taking notes for asking other teams questions and preparing key points for the debaters to respond or argue back during the debate. However, if a group eventually has three members, each member may have to ask and answer the questions after their parts and earn extra marks.

\section{Mutual dependency}

Each team member has to attentively prepare his/her arguments in order to make their team win the debate and earn extra points. Moreover, every student has to obtain the information (the arguments) from one another in order to answer the reflection questions on the causes of war from each country's point of view precisely.

\section{Example 3 proxy war case-based group discussions}

Since the objectives of this lesson are 1) to understand the concept of proxy wars and 2) to explore the impact of the Cold War on the Third World, the case studies of Korean War and Vietnam War were used as the sources of information for critical analysis. Firstly, students were separated into groups to read different parts of the assigned reading and take turns summarizing it for their fellow group members. In addition, they were asked to read some assigned testimonials out loud as if they were sharing their personal stories with their friends. Secondly, They were assigned to meet up with someone from another group and take turns teaching each other about their own reading in order to work together to compare and contrast the wars using the Venn Diagram. The application of the combining arrangement strategy in regard to speaking opportunities is explained below.

\section{Split information}

Firstly, students are divided into 8 groups. Four of them read the reading about the Korean War while the other four read the reading about the Vietnam War. In each group, a student reads about the causes of the war, another student reads about what happened during the war, and the last student reads about the conclusion of the war. Afterwards, each of them will get a testimonial to read 'out loud' in order to share the information to their classmates as if they were the authors of the testimonials.

\section{Individual task}

After reading the given readings, each student summarizes his/her part and shares the information to his/her teammates in order to complete their individual worksheets together. Moreover, each student has to read his/her assigned testimonial as if $\mathrm{s} / \mathrm{he}$ was the author of the testimonial to create the sense of real-life experience sharing in class.

\section{Mutual dependency}

Not only helping each other summarizing the passages, students have to summarize what happened to the people who were involved in the war according to the wartime testimonials they learned from one another. Afterwards, they have to share what they know about their assigned proxy war to another team who study about another proxy war. Then, each two teams consisting of a Korean War expert team and a Vietnam War expert team has to help each other compare and contrast the proxy wars.

\section{FINDINGS AND DISCUSSION}

To complete this research, the author had analyzed the data collected for answering the research questions. The quantitative data is interpreted in a descriptive form, and is used for supporting the qualitative results. This section comprises the presentation and interpretation of the findings resulting from the pre-intervention and post-intervention surveys, including the students' reflections and the researcher's observation. 


\section{Analysis of Pre- and Post-intervention Surveys}

The researcher had conducted the post-intervention survey in the late of April 2018. There were 43 respondents (or $90 \%$ of the total samples). Compared to the previous survey, there were six more students who were present in class on the day that the survey was carried out. Therefore, when comparing the pre- and post-intervention survey results, the researcher focused on the percentage difference. Some minor changes in students' English competency demographics were evident as well as their preferences in terms of classroom activities. Moreover, the postintervention survey demonstrated the students' feedback on the intervention which will be discussed in this section, too.

First of all, in terms of their English proficiency, out of 43 respondents, 23 students (54\%) anonymously answered that they have an intermediate level of spoken English, 15 students (35\%) believed that they have a basic level of spoken English, and 5 students (12\%) answered that they have a high level of spoken English. Considering the higher num- ber of respondents participating in the second survey, these statistics actually show the resemble trend to the first survey. When comparing themselves with other students in their classes, 27 students (63\%) believed that they have the same level of spoken English, 7 students (16\%) considered that they have a higher level of spoken English, and 9 students (21\%) supposed that they have a lower level of spoken English. Again, the results from the post-intervention survey were quite similar to the pre-intervention survey results. However, there were the increase in the percentage of students who believed they have a lower level of spoken English and the decrease in the percentage of students who regarded their level of spoken English as higher. Still, considering the equal number of students who responded that they have a higher level of English from both surveys (which were 7 out of 37 in the first survey and 7 out of 43 in the second survey, respectively), it can be assumed that several students who participated only in the second survey were those with lower level of spoken English from their point of view.

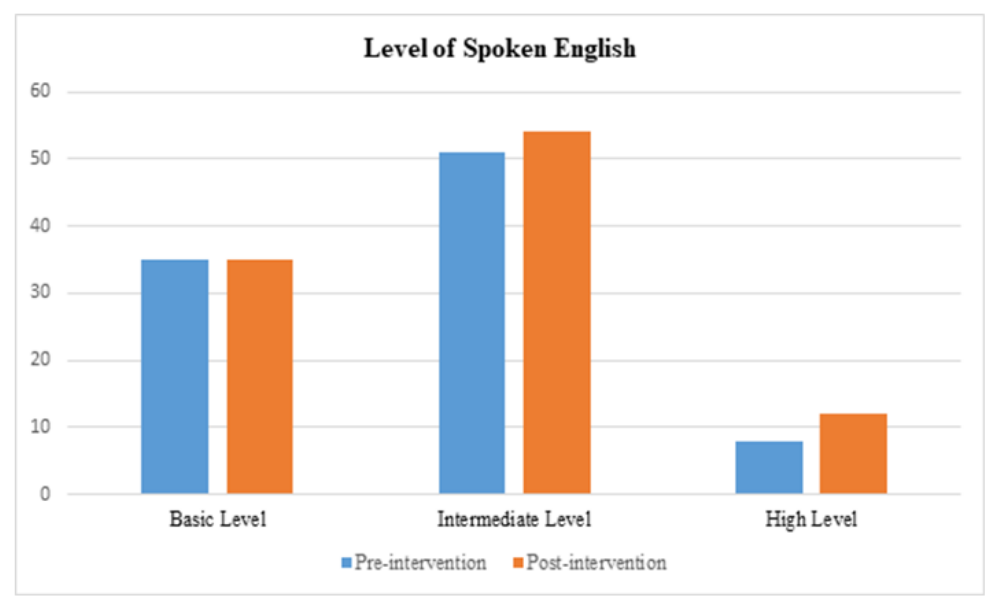

FIGURE 2. Students' self-evaluation of their spoken English (\%)

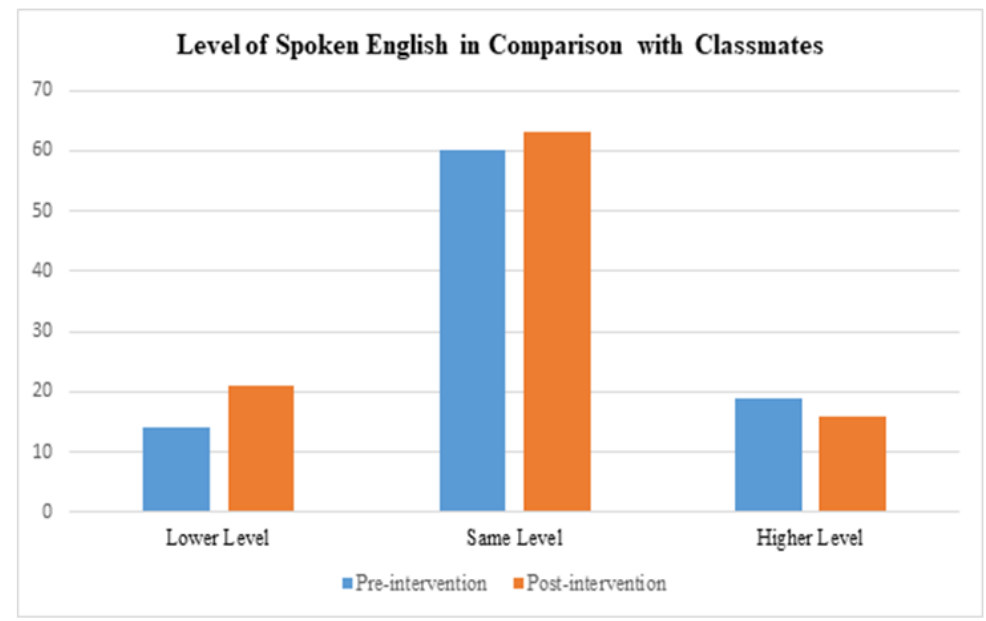

FIGURE 3. Students' self-evaluation of their spoken English compared with their classmates (\%) 
Second, from the post-intervention survey, there was a rise in students' comfortability when they spoke with their partners or discussed in a small group or even when they needed to present something to the whole class. Out of 43 students, $88 \%$ were comfortable or very comfortable to speak English with their partners in pair, and 90\% were comfortable or very comfortable to have a small group discussion in English. Compared to the pre-intervention period, students' comfortability had been increased by $8-10 \%$. Interestingly, the survey results show that more students felt comfortable or very comfortable when they had to speak or present something to the class $(68 \%>70 \%)$, but there were also few more students who felt a little uncomfortable or very comfortable to answer the teacher's questions in front of the class $(38 \%>44 \%)$. This could be because students were also required to answer more questions or make more decisions during the intervention ac- tivities, so they were worried about making any mistakes. After participating in this semester activities, $79 \%$ of the respondents learned that they preferred to do speaking activities in pair or with a small group of three or four classmates while $21 \%$ of them preferred to do the activities with the whole class. Compared to the previous survey results, there were $1 \%$ increase in the number of students who would like to do speaking activities with a partner or in a small group and $7 \%$ increases in the number of students who would like to do the activities with the whole class, respectively. This confirmed that students were more likely to enjoy the speaking activities either in pair or in a small group, but they also learned that they could comfortably and willingly involve in the whole-class speaking activities. However, none of the students preferred to do speaking activities in a large group of about 10 classmates.

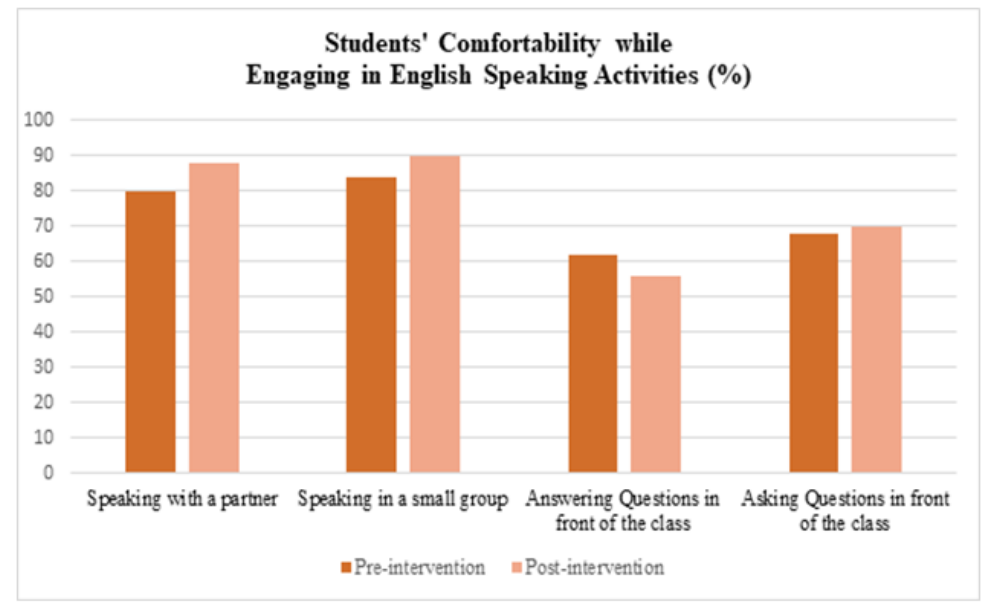

FIGURE 4. Students' comfort ability while engaging in English speaking activities (\%)

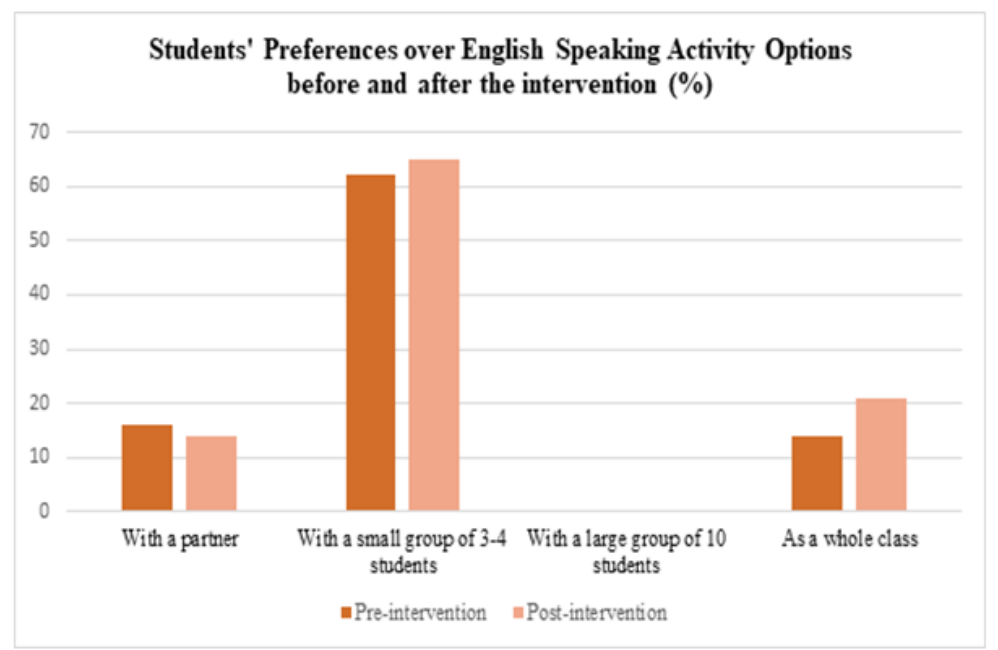

FIGURE 5. Students' preferences over English speaking activities before and after the intervention (\%) 
Third, regarding the increased English speaking opportunities, the post-intervention survey conducted in the second semester shows that 17 students out of 41 respondents (40\%) participated in English speaking activities quite often; this is equal to $21 \%$ increase compared to the first semester. Proportionately, it is important to note that there were 20 students (49\%) participated in English speaking activities only sometimes in class (apart from the quarter project period) in this semester, which means there was $26 \%$ decrease in the number of students who sometimes participated in English speaking activities. The number of students who believed that they spoke in English very often in this class stayed the same (3 students; $8 \%$ in the first survey or $7 \%$ in the second survey, respectively). There was a student who responded that s/he never participated in English speaking activities; nonetheless, this could be another respondent error. Not only the frequency of the intervention activities implementation, but students' opinions on the following statement - " Compared to the last term, I have more opportunities to speak English in class this semester" was also another evidence showing that the intervention could effectively promote English speaking opportunities in large classes. Even though 22 students out of 43 respondents (52\%) felt neutral about the statement, 19 students $(44 \%)$ agreed on the fact that they had more English speaking opportunities in class compared to the previous semester, and a student (2\%) strongly agreed on the same fact; this can be assumed that the intervention activities could encourage almost half of the students (46\%) to speak English in class. There was only one student (2\%) who disagreed with the statement.

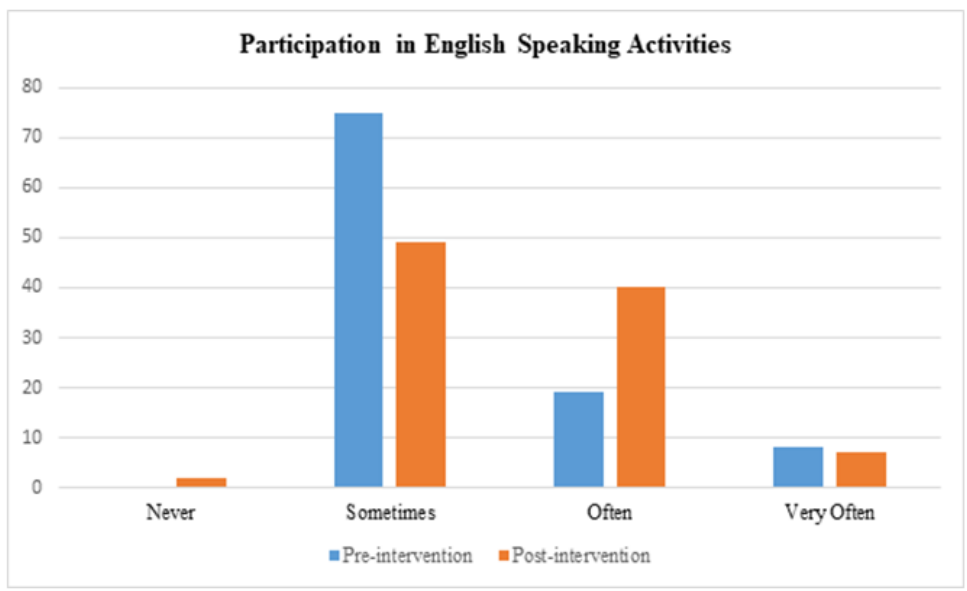

FIGURE 6. Students' participation in English speaking activities (\%)

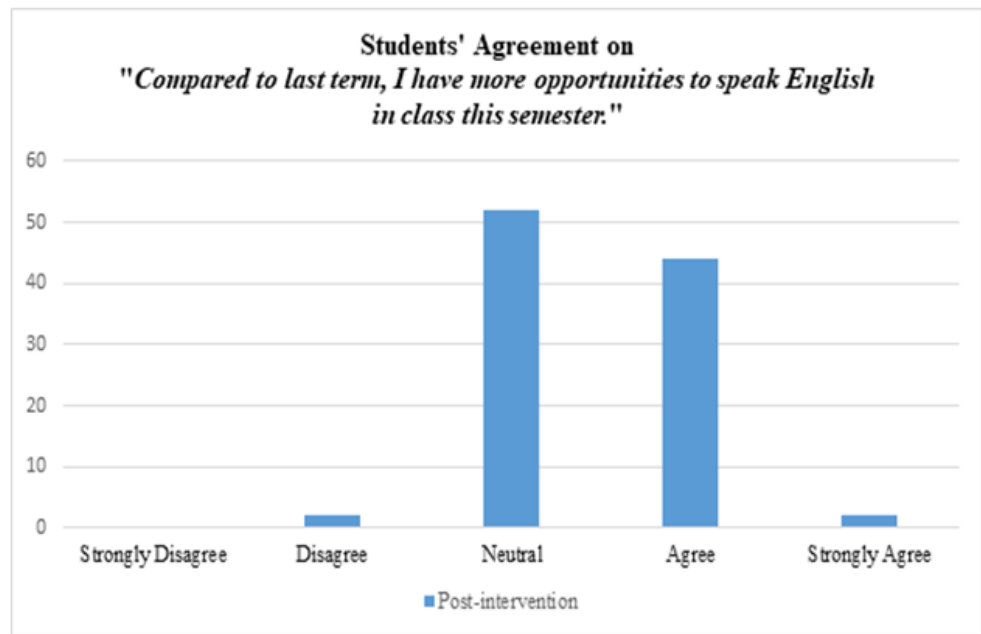

FIGURE 7. Students' agreement on the increase of English speaking opportunities in class (\%) 
Fourth, according to the post-intervention survey results, a number of students had voluntary listed their favorite English Speaking activities in Semester Two as follows. To begin with, the most popular activity is the Imperialism Board Game by which 10 students mentioned it the questionnaire. Two of them explained that it is the best activity for practicing English speaking skills because they were required to communicate with the whole class in English and read the card descriptions out loud. Other two students supported that they felt more comfortable to speak English whiling playing this game with the whole class. The other comments for this activity include 'fun and not too serious', 'competitive', 'everyone can participate', and 'express ideas more freely'. Next, 9 students stated that "Who Started the WWI?" Debate is their favorite English speaking activities. A student pointed out that $\mathrm{s} / \mathrm{he}$ felt comfortable and more confident during the activity because students could prepare their own speeches beforehand. Two students affirmed that they had gained more vocabularies and expressions from the debate. Another student expressed that the topic of the debate as well as the storyline behind it interesting and challenging. S/he also said that the debate promotes the positive competition among the students as they could rebut one another. Apart from other simulations or giving a role-play speech which were the most noticed activities from the students' point of view, 3 students specifically identified case-based group discussions as their favorite English speaking activities. Two of them explained that sharing information after reading the texts or reading the texts out loud encouraged them to speak more. Correspondingly, two students asserted that speaking with a partner or in a small group made them feel more relaxed and effectively gain new vocabularies.

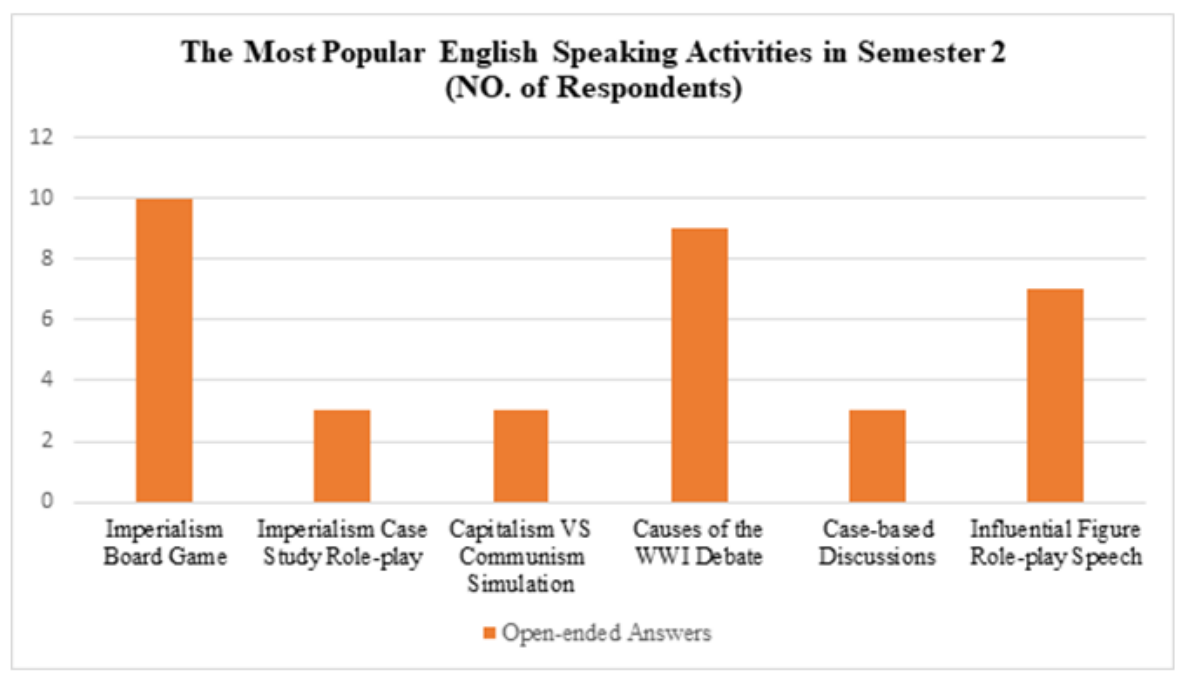

FIGURE 8. The most popular english speaking activities in semester 2 (no. of respondents)

Regarding the suitable environment for combining arrangement activities, 19 students out of 47 (44\%) agreed that the new seating chart (E-shape) encouraged them to speak more; that was almost half of the class. 22 students (51\%) felt neutral towards the statement and 4 students (9\%) disagreed with the statement. Even though they did not give a reason why they disagreed with the statement, but according to the researcher's observation, some students felt pressured when they were asked a question one by one following the seating order. Furthermore, regarding the time they had in class for the activities, 33 students (77\%) believed they had enough time to prepare for each activity. 9 students (21\%) claimed that they did not have enough time to prepare while one student (2\%) stated that s/he had too much time to prepare him/herself for the activities. In com- parison with the first survey results, the majority were still able to complete the tasks in time.

\section{Analysis of Students' Reflection Notes}

The effectiveness of the intervention activities could be proven by the excerpts of anonymous students' reflection notes from different lessons. This section aims to present the students' perspectives on the activities as well as how they reflected their learning from them. The researcher selected some examples of the students' reflection notes from the examples of intervention activities mentioned earlier.

\section{Example 1 imperialism simulation board game}

From the students' reflection notes, this activity was considered as a fun and challenging activity which effectively 
taught/helped them review about imperialism. According to the instructions, most students explained how the game taught about the key concepts they learned from the previous semester in detail; however, there were also some students who provided their insights about the game. A student stated that the researcher came up with the new method of teaching. The game made her realize how the imperialism worked during the pre-WWI era and that each country had to be very careful with every move in order to conquer other lands and protect their own lands at the same time. Another student wrote that this game was quite effortful because any action could result into different results. Moreover, a number of students mentioned about how the teacher productively involved in the game, for example, a student said the teacher demonstrated how to play this game wisely and steal lands from the others. From the researcher's observation, each student gradually got used to announcing his/her team's choice in English to the class and repeating the card descriptions when their classmates asked them to. This helped the students practice their English speaking skills efficiently.

\section{Example 2 causes of the World War I role-play debate}

For this activity, each student had to submit a worksheet which reflects their learning while participating in the debate. Nevertheless, apart from answering the reflection questions, some students also provided some extra comments on the activity (See examples in Appendix H). A student described her learning experiences as follows: first, the topic was interesting and appealing to learn about from the beginning; second, students thoughtfully prepared for their debate by making the scripts. This student also helped her teammates by giving some advice about how to speak and where to focus on in the script in order to perfectize the speech. Another student stated in her reflection note that this activity was more serious than expected. She wrote that her responsibility was the opening statement which means she had to lead the first strike, and in order to do so, she needed to get enough information and prepare a lot. Both students as well as the rest of the class showed their in-depth understanding by explaining how the WWI started and who should be blamed, including why and why not, in detail. According to the researcher's observation, students learned certain vocabularies and expressions from the debate accurately, especially the key concepts about the WWI and some sentence frames for debating. Because they knew that their oral skills might affect the whole team's grade, they practiced hard. For some proficient students, they chose to be the Q\&A interrogators because they real- ized that this role requires quick-thinking ability as well as good speaking skills to convey messages thoughtfully and convincingly with a low chance of preparation. Furthermore, since each team represented a specific country's government, they easily became empathetic towards the country's situation or spoke from their hearts as if they were some characters from a wartime movie.

\section{CONCLUSION}

To sum up, the goal of this study is to explore the alternative or suitable activities to promote English speaking opportunities in large classes based on the idea of combining arrangement strategy. The researcher chose the population in this project in regards to the fact that Thai students at the case-study school were persistent to use their native language when talking or discussing with their classmates. Additionally, $75 \%$ of the samples responded to the preintervention survey that they participated in English speaking activities only sometimes in class while $25 \%$ of the samples stated that they either often or very often participated in English speaking activities. So, the researcher considered their classes as large classes, and it is necessary to give more opportunities to speak English in class for more than half of them. Even though $57 \%$ of the respondents from the first survey felt neutral towards their current amount of opportunity to speak English in class, 38\% students either agreed or strongly agreed that they wanted more English speaking opportunities in class. In terms of the competency demographics, there was no significant change in their level of speaking skills after the intervention. The majority of the students still rated their English speaking skills at the intermediate level like their classmates.

Focusing on the research questions and in conformity with the hypotheses, the research findings show that 1) combining arrangement activities can effectively promote English speaking opportunities in large classes. There was $21 \%$ increase in the number of students who often participated in English speaking activities while there was 26\% decrease in the number of students who only sometimes participated in such activities. Compared to the previous term, although $52 \%$ felt neutral towards this fact, $46 \%$ of the students supported that the intervention activities effectively increased their English speaking opportunities in class. 2) In this study, the essential elements of the design of combining arrangement activities used for increasing English speaking opportunities among the ESL learners in large classes are split information, individual task , mutual dependency, E-shape seating arrangement, direct communication, self-reflection, individual grading , 
problem-solving or critical thinking experiences, and entertaining or interesting contents. 3) From the intervention results, the researcher discovered that examples of combining arrangement activities suitable for promoting English speaking opportunities in large classes and increasing students' learning motivation simultaneously were simulation games, role-plays and role-play speeches, and case-based group discussions. From the respondents' point of view, these activities encouraged them to communicate with the whole class in English, learn new vocabularies and expressions, promote competitiveness and teamwork, and reduce the learners' stress with fun and low-pressure environment.

\section{LIMITATIONS AND RECOMMENDATIONS}

This study was confronted by a number of limitations as listed below:

- Many prospective samples were absent when the surveys were carried out. Since the surveys were anonymousbased, the researcher did not want to approach the absent students and force them to complete the questionnaires.

- Many samples made a lot of respondent errors, but because they anonymously answered the questionnaires, the researcher could not ask them to change or input the answers.

- A few samples returned the questionnaires by leaving the forms on the researcher's office desk, but did not write their section number on the forms. Hence, the researcher had to combine the results from the two classes together before analyzing the statistics.

- The questionnaires were paper-based. With the hard copies, running the statistics automatically was not an option unless all the data had been input in a statistical analysis program; nonetheless, that kind of process still takes a lot of time. The researcher had tried web-based survey for the post-intervention survey, but many recipients ignored the request to complete the questionnaire. This resulted in the low response rate, and required the researcher to conduct another paper-based survey for the post-intervention. - Time limitation caused difficulties in the execution of this action research. The samples were given only 20 minutes in class to complete each questionnaire in order to avoid interrupting their learning experiences as much as possible. Regarding the limitations and some deficiencies of this study, the following recommendations should be made in the future research:

- Any survey should be conducted on the day that every sample is present, or an alternative data collection method should be used. The researcher should avoid rushed or short data collection periods because the level of nonresponse bias will climb dramatically if the time frames are not flexible enough for the respondents to answer the survey. There must be a structural system for collecting and storing the documents like questionnaires, too.

- A similar study can be conducted with a larger sample size to explore the more diverse demographic information and verify the research findings.

- The researcher should remind the respondents to answer every question and fill in all of the necessary demographic information.

- An incentive such as snacks can be used for motivating the samples to participate in the study. The time length of the survey should be extended in order to facilitate the respondents.

- Compute descriptive statistics and statistical tests such as T-Tests, ANOVAs, regressions and correlations should be applied in a similar study.

- For the future use of the research findings, it is recommended to further evaluate the relationship between students' self-perception on their performance and their actual capabilities, or assess the impact of ESL learners' selfperception on their low rate of English speaking in class.

\section{REFERENCES}

Abdul Amir, A. R. Z. (2015). Utilization of request mitigators by Omani learners of English and native speakers: A comparative study. International Journal of Humanities, Arts and Social Sciences, 1(4), 156-172. doi:https://doi.org/10.20469/ ijhss.20004-4

Al-Jarf, R. (2006). Large student enrollments in EFL programs: Challenges and consequences. Asian EFL Journal Quarterly, 8(4), 8-34. doi:https://doi.org/10.4324/9781315755243-8

Azmin, N. H. (2016). Effect of the jigsaw-based cooperative learning method on student performance in the general certificate of education advanced-level psychology: An exploratory brunei case study. International Education Studies, 9(1), 91-106. doi:https://doi.org/10.5539/ies.v9n1p91

Bahanshal, D. A. (2013). The effect of large classes on English teaching and learning in Saudi secondary schools. English Language Teaching, 6(11), 49-56. doi:https://doi.org/10.5539/elt.v6n11p49 
Boonyarattanasoontorn, P. (2017). An investigation of Thai students' English language writing difficulties and their use of writing strategies. Journal of Advanced Research in Social Sciences and Humanities, 2(2), 111-118. doi:https://doi.org/ 10.26500/jarssh-02-2017-0205

Charoensuk, V., \& Jaipetch, D. (2017). Attitudes toward English: A study of first-year students at King Mongkut's University of Technology North Bangkok. Journal of Advances in Humanities and Social Sciences, 3(1), 42-57. doi:https://doi.org/ 10.20474/jahss-3.1.4

Department of Education and Early Childhood Development of Newfoundland and Labrador. (2009). Who is the ESL student? Retrieved from https://goo.gl/xF6pXZ (acessed on 14 October, 2011)

DiNitto, R. (2000). Can collaboration be unsuccessful? A sociocultural analysis of classroom setting and japanese 12 performance in group tasks. The Journal of the Association of Teachers of Japanese, 34(2), 179-210. doi:https://doi.org/ $10.2307 / 489553$

Harmer, J. (2008). How to teach English. ELT Journal, 62(3), 313-316. doi:https://doi.org/10.1093/elt/ccn029

Hayes, D. (1997). Helping teachers to cope with large classes. ELT Journal, 51(2), 106-116. doi:https://doi.org/10.1093/ elt/51.2.106

Hilao, M. P. (2016). Creative teaching as perceived by English language teachers in private universities. Journal of Advances in Humanities and Social Sciences, 2(5), 278-286. doi:https://doi.org/10.20474/jahss-2.6.4

Hill, G. W. (1982). Group versus individual performance: Are N+ 1 heads better than one? Psychological Bulletin, 91(3), 517-539. doi:https://doi.org/10.1037/0033-2909.91.3.517

Johnson, D. W., \& Johnson, R. T. (1999). Making cooperative learning work. Theory into Practice, 38(2), 67-73. doi:https:// doi.org/10.1080/00405849909543834

Junnak, C., \& Veerachaisantikul, A. (2016). Reporting verb in research projects of EFL English major students. JJournal of Advanced Research in Social Sciences and Humanities, 1(1), 41-46. doi:https://doi.org/10.26500/jarssh-01-2016 $-0105$

Ky, L. H. (2002). Problems, solutions, and advantages of large classes. Retrieved from https://goo.gl/918zMv (accessed on 14 June, 2008)

Lin, L. (2015). Exploring collaborative learning: Theoretical and conceptual perspectives. In Lin, L (Ed.), Investigating Chinese HE EFL classrooms. New York, NY: Springer.

Long, M. H., \& Porter, P. A. (1985). Group work, interlanguage talk, and second language acquisition. TESOL Quarterly, 19(2), 207-228. doi:https://doi.org/10.2307/3586827

Mala, N. (2004). The effect of u-shape (horseshoe) seating arrangement on speaking ability of the tenth grade students at smk ti airlangga samarinda (Unpublished master's thesis). English Department, Mulawarman University, Samarinda, Indonesia.

Marzano, R. J., Marzano, J. S., \& Pickering, D. (2003). Classroom management that works: Research-based strategies for every teacher. Alexandria, VA: ASCD.

Meng, F. (2009). Encourage learners in the large class to speak English in group work. English Language Teaching, 2(3), 219-230. doi:https://doi.org/10.5539/elt.v2n3p219

Minchen, B. J. (2007). The effects of classroom seating on students' performance in a high school science setting. (Unpublished master's thesis). State University of New York, New York, NY.

Miyake, N. (1986). Constructive interaction and the iterative process of understanding. Cognitive Science, 10(2), 151-177. doi:https://doi.org/10.1207/s15516709cog1002_2

Negash, N., \& Shamim, F. (2007). Maximizing learning in large classes: Issues and options. Retrieved from https://goo.gl/ bHPfCp (accessed on 14 July, 2017)

Slavin, R. E. (1988). Cooperative learning and student achievement. Retrieved from https://goo.gl/T3PvNA (accessed on 1 January, 2018)

Smith, B. L., \& MacGregor, J. T. (1992). What is collaborative learning. Pennsylvania, PA: Pennsylvania State University Press.

Smith, K. A., Sheppard, S. D., Johnson, D. W., \& Johnson, R. T. (2005). Pedagogies of engagement: Classroom-based practices. Journal of Engineering Education, 94(1), 87-101. doi:https://doi.org/10.1002/j.2168-9830.2005.tb00831.x

$\mathrm{Su}$, S.-C., \& Liang, E. (2017). Action research of the Multiple Intelligence (MI), cooperative learning, and game-based teaching into summer intensive English classes for mixed-level and mixed-age students. Universal Journal of Educational 
Research, 5(11), 1977-1985. doi:https://doi.org/10.13189/ujer.2017.051114

Taher, M. A., Shrestha, P. N., Rahman, M. M., \& Khalid, A. K. M. I. (2016). Curriculum Linked Video (CLV) as a tool for English Language Teaching (ELT) at secondary school classrooms in Bangladesh. International Journal of Humanities, Arts and Social Sciences, 2(4), 126-132. doi:https://doi.org/10.20469/ijhss.2.20002-4

Woolfolk, A. (2004). Educational psychology. Boston, MA: Pearson Education Inc.

$\mathrm{Yu}, \mathrm{J}$. (2004). Problems and strategies of teaching English in large college classes. Journal of Chongqing University of Post and Telecommunication (Social Science), 3(1), 139-140. 